\title{
Tachykinin Receptor 3 Distribution in Human Oral Squamous Cell Carcinoma
}

\author{
KYOICHI OBATA ${ }^{1}$, TSUYOSHI SHIMO ${ }^{1}$, TATSUO OKUI ${ }^{1}$, KENICHI MATSUMOTO ${ }^{1}$, \\ HIROYUKI TAKADA ${ }^{1}$, KIYOFUMI TAKABATAKE ${ }^{2}$, YUKI KUNISADA ${ }^{1}$, \\ SOICHIRO IBARAGI ${ }^{1}$, HITOSHI NAGATSUKA ${ }^{2}$ and AKIRA SASAKI ${ }^{1}$ \\ ${ }^{1}$ Department of Oral and Maxillofacial Surgery, \\ Okayama University Graduate School of Medicine, Okayama, Japan; \\ ${ }^{2}$ Department of Oral Pathology and Medicine, Okayama University Graduate School of Medicine, \\ Dentistry and Pharmaceutical Sciences, Okayama, Japan
}

\begin{abstract}
Background: Tachykinin 3 (TAC3) and its preferred tachykinin receptor 3 (TACR3) that are prominently detected in the central nervous system, play significant roles in physiological development and specifically in the human reproductive system. The roles of TAC3/TACR3 in oral squamous cell carcinoma are unknown. Materials and Methods: We examined the expression pattern of TAC3/TACR3 in clinically-resected oral squamous cell carcinoma samples using immunohistochemistry and immunofluorescence analysis. Results: We found that even though the expression level of TACR3 was negative in the normal epithelium, it was highly elevated in tumor cells. A more intense signal was observed in the invasive front of tumor cells that had migrated into the mandible bone matrix. TAC3 was not detected in tumor cells, but was expressed in PGP-9.5-positive sensory nerves in the mandible. Conclusion: Our results suggest that peripheral sensory nerve-derived TAC3 may affect gingival oral squamous cell carcinoma cells through TACR3 in the bone matrix.
\end{abstract}

Tachykinins are a family of neuropeptides distributed in the mammalian central and peripheral nervous system $(1,2)$. Tachykinins are characterized by a common C-terminal structure (Phe-Xaa-Gly-Leu-Met-NH2) and include TAC1-3 (3). Their actions are mediated by three different receptors, TACR1-3 belonging to the superfamily of G protein-coupled receptors (4).

Correspondence to: Tsuyoshi Shimo, D.D.S., Ph.D., Department of Oral and Maxillofacial Surgery, Okayama University Graduate School of Medicine, Dentistry and Pharmaceutical Sciences, 2-5-1 Shikata-cho, Kita-ku, Okayama 700-8525, Japan. Tel: +81 862356702, Fax: +81 862356704, e-mail: shimotsu@md.okayamau.ac.jp

Key Words: Tachykinin receptor 3, tachykinin 3, oral squamous cell carcinoma.
Previously, the expression of TACR 3 was considered to be restricted to the central nervous system, including the cortex, nuclei of the amygdala, hippocampus and midbrain $(5,6)$. TAC3 and TACR3 modulate the GnRH release at the hypothalamic-pituitary axis $(7,8)$ and their participation in the human reproduction system is clear from the fact that mutations of TAC3 and TACR 3 are associated with human normosmic hypogonadotropic hypogonadism, a disease characterized by the failure of sexual maturation, impaired gametogenesis and infertility $(9,10)$. TAC 3 is indispensable to physiological development and human reproductive system (11). The reproductive hormone signaling cascade have found extensive applications in treating a wide range of hormonedependent diseases such as prostate (12) and lung cancer (13).

Sex hormone receptors have also been involved in headand-neck squamous cell carcinoma (14). Despite this fact, the role of reproductive factors in oral squamous cell carcinoma remains unclear (15) and the role of TAC3/TACR3 in cancer has not yet been reported.

In this study, we analyzed the expression pattern of TACR3 in early and advanced oral squamous cell carcinoma, and how TACR3 signaling was involved in tumor invasion in bone matrix.

\section{Materials and Methods}

Patients. The eight patients included in the study were diagnosed and treated for lower gingival, tongue, mouth floor or buccal squamous cell carcinoma individually at Okayama University Hospital (Okayama, Japan) in the years 2000-2013, with clinicopathological confirmation of the diagnosis. The surgically resected mandibles were collected as part of routine care by the authors. No patient had received chemotherapy or radiation therapy before surgery. The retrospective study was approved by the Ethical Committee of the Okayama University Graduate School of Medicine, Dentistry and Pharmaceutical Sciences (Protocol No: 1949). Written consent was not acquired, but an announcement of the study was posted prominently in adjacent clinics. The authors had access to patients' records prior to data anonymization. 


\begin{tabular}{|c|c|c|c|c|c|}
\hline Organ & Diagnosis & TACR3 & Organ & Diagnosis & TACR3 \\
\hline $\begin{array}{c}\text { Cerebral } \\
\text { cortex }\end{array}$ & Normal & & \multirow{2}{*}{ Maxilla } & \multirow{2}{*}{ SCC } & \\
\hline Esophagus & Normal & & & & \\
\hline Kidney & Normal & & \multirow{2}{*}{ Mandible } & \multirow{2}{*}{ SCC } & \\
\hline Liver & Normal & & & & \\
\hline Lung & Normal & & \multirow{2}{*}{ Mouth floor } & \multirow{2}{*}{ SCC } & \\
\hline Ovary & Normal & & & & \\
\hline Pancreas & Normal & & \multirow{2}{*}{ Pharynx } & \multirow{2}{*}{ SCC } & \\
\hline Parathyroid & Normal & & & & \\
\hline $\begin{array}{c}\text { Pituitary } \\
\text { gland }\end{array}$ & Normal & & \multirow{2}{*}{$\begin{array}{l}\text { Parotid } \\
\text { gland }\end{array}$} & \multirow{2}{*}{ SCC } & \\
\hline Placenta & Normal & & & & \\
\hline Prostate & Normal & & \multirow{2}{*}{ Head skin } & \multirow{2}{*}{ SCC } & \\
\hline Spinal cord & Normal & & & & \\
\hline
\end{tabular}

Figure 1. TACR3 expression in human normal organ tissue and head-and-neck disease tissue array. SCC: Squamous cell carcinoma.

Histochemical and immunohistochemical analysis of surgically resected samples. After resection, formalin-fixed mandible segments were embedded in paraffin and sectioned at $4 \mu \mathrm{m}$ intervals. Also used in the tissue microarray were 35 types of normal human tissue, 90 cases/ 96 cores (MNO961, US Biomax, Rockville, MD, USA) as control samples, and a head-and-neck disease tissue samples, 48 cases/96 cores (HNT961, US Biomax)

The sections were deparaffinized and subjected to antigen activation with $1.25 \%$ hydrogen peroxide solution (Wako, Osaka, Japan) containing methanol (Wako) for $30 \mathrm{~min}$. Slides were incubated in Tris-EDTA (Sigma-Aldrich, St. Louis, MO, USA) for 2 min using a pressure cooker. After reaching room temperature, they were blocked with the peroxidase-blocking reagent included in the EnVision FLEX Mini Kit High pH (Dako, Carpinteria, CA, USA) for 5 min. Anti-TACR3 (\#bs-0166R, rabbit IgG, BIOSS, Woburn, MA, USA), anti-TAC3 (\#NB300-201SS, rabbit IgG, Novus Biologicals, Littleton, CO, USA), anti-cytokeratin-13 (CK13, \#ab16112, mouse IgG, Abcam, Cambridge, UK), and anticytokeratin-17 (CK-17, \#M7046, rabbit IgG, Dako) antibodies were used for the immunohistochemical analysis. The specimens were incubated with antibody overnight at $4{ }^{\circ} \mathrm{C}$, followed by washes with PBS. The slides were then treated with HRP (Dako) for $20 \mathrm{~min}$ at room temperature. The immunoreaction was visualized using DAB+ Chromogen (Dako), and counterstaining was performed with Hematoxylin QS (Vector, Burlingame, CA, USA).

Immunofluorescence. Control and disease specimens were deparaffinized and incubated in Tris-EDTA (Sigma-Aldrich) for 2 min using a pressure cooker. Sections were blocked with Block Ace (DS Phama, Osaka, Japan) for $30 \mathrm{~min}$, then immunolabeled with primary antibody anti-TAC3 (Novus Biologicals) and anti-Protein Gene Product 9.5 (PGP-9.5) (\#ab8189, mouse IgG, Abcam) overnight at $4{ }^{\circ} \mathrm{C}$. The target protein was visualized by incubation with anti-rabbit IgG Fab2 Alexa Fluor 488 (\#4412S, Cell Signaling, Danvers, MA USA) and Anti-mouse IgG Fab2 Alexa Fluor 647 (\#4410S, Cell Signaling) for $30 \mathrm{~min}$. Coverslips were mounted with ProLong Gold Antifade with DAPI (\#8961S, Cell Signaling) and sealed with nail polish. 

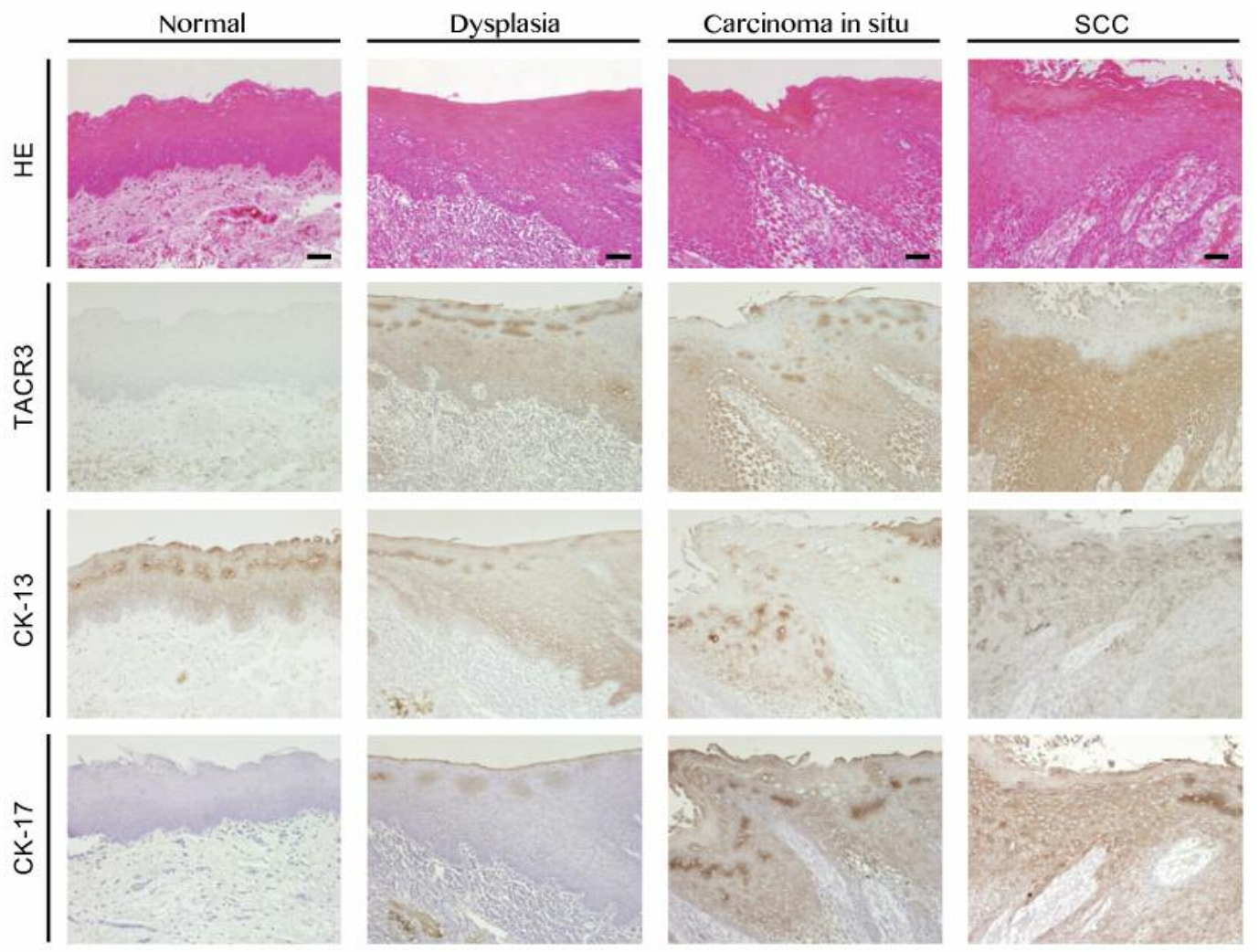

Figure 2. Expression of TACR3 in normal, dysplasia, carcinoma in situ and carcinoma region in the gingival epithelium. Hematoxylin and eosin (H\&E) staining, immunostaining for TACR3, CK-13 and CK-17. Bar, $50 \mu \mathrm{m}$.

\section{Results}

The expression of TACR3 in gingival squamous cell carcinoma. Most previous TACR3 studies identified the protein in the central nervous system. To evaluate the TACR3 expression in normal and diseased organs, paraffin tissue microarrays were performed. As shown in Figure 1, TACR3 was expressed not only in the cerebral cortex and pituitary gland, but also in the esophagus, kidney, liver, lung, ovary, pancreas, parathyroid, placenta, prostate and spinal cord. In the pathological condition, TACR3 was expressed in the oral squamous cell carcinoma in head-and-neck tumors (Figure 1).

To further investigate the expression of TACR 3 in human gingival squamous cell carcinoma, we performed immunohistochemical staining using specific antibodies. TACR3 was not detected in the normal gingival epithelia (Figure 2). In sharp comparison with normal epithelia, TACR3 was detected in dysplasia and carcinoma in situ and was more expressed throughout the whole squamous cell carcinoma area (Figure 2). All cases with the invasive phenotype showed a strong intensity of TACR3 immunoreactivity. To confirm the stage of epithelial neoplasia, expressions of CK-13 and CK-
17 were examined. CK-13 was expressed in the normal epithelium and dysplasia, with a tendency of lower expression in malignant transformation. CK-17 was not expressed in the normal epithelium and dysplasia, but was found in carcinoma in situ and squamous cell carcinoma (Figure 2). These results suggested that TACR3 expression might be useful for detecting neoplastic lesions, specifically oral squamous cell carcinoma. This expression was also observed in all cases of tongue, mouth floor and buccal squamous cell carcinoma $(n=8$ individually, Figure 3).

TACR3 expression in osteolytic mandible squamous cell carcinoma. Figure 4 shows representative microscopic images of invasive bone destruction observed out of the 8 patients with oral squamous cell carcinoma in the mandible region. TACR3 was weakly expressed in tumor cells located at the surface of the epithelium. However, more intense TACR3 signals were observed in tumor cells that had invaded the bone matrix (Figure 4). On the other hand, TAC3 was not detected in tumor cells, but strongly expressed in PGP-9.5-positive the highly specific marker for neurons, mandibular sensory nerve (Figure 4). 


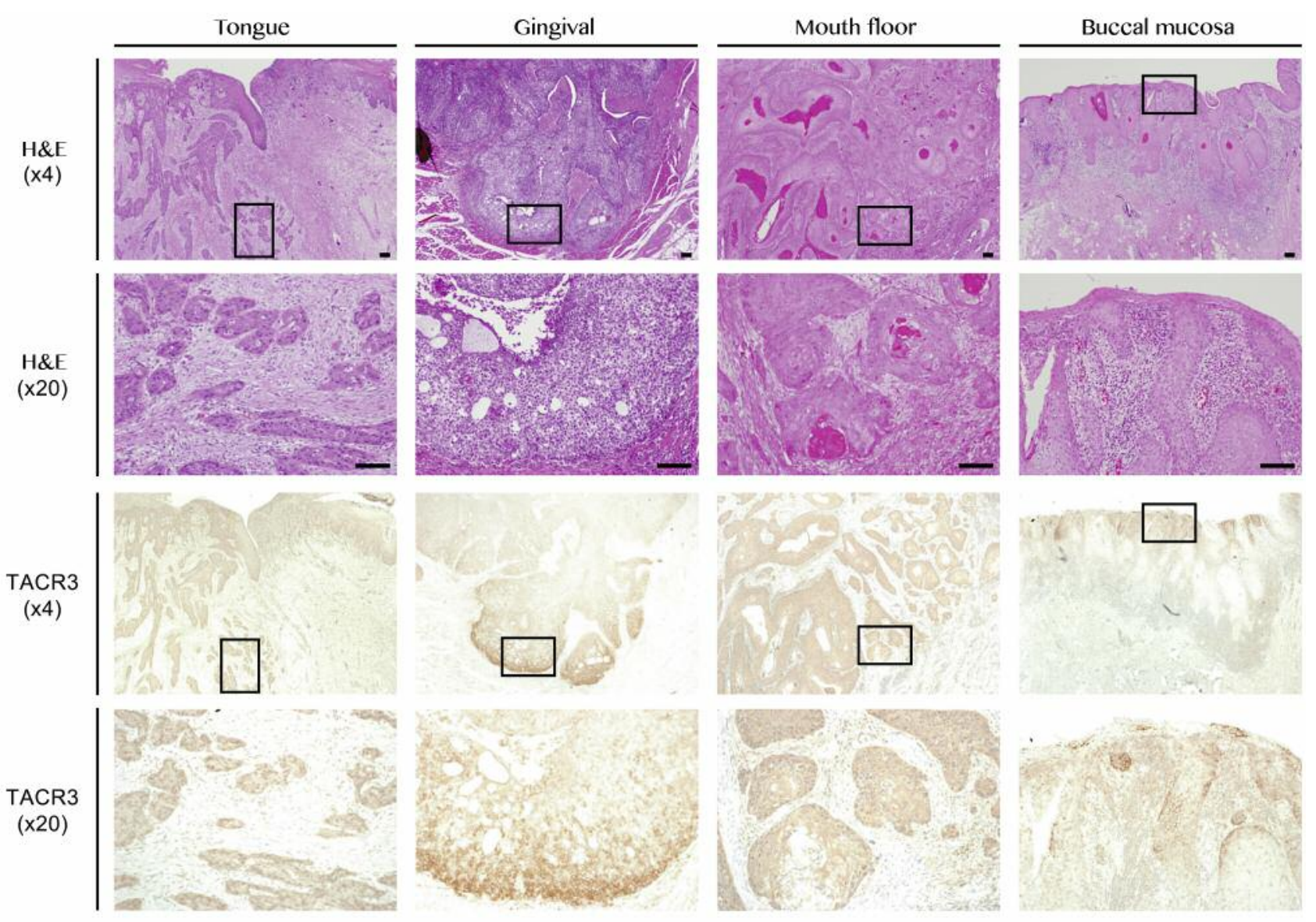

Figure 3. H\&E staining and the immunohistochemistry results for TACR3 in tongue, gingiva, mouth floor and buccal oral squamous cell carcinoma. Bar, $50 \mu \mathrm{m}$.

\section{Discussion}

Evidence is increasing that the regulation of the reproductive signaling pathways by the tachykinin peptide family and their receptors occurs not only at the CNS level, but also in the peripheral organs $(16,17)$. The exact pathological role of TACR3 in oral squamous cell carcinoma remains unclear. In this study, we analyzed the expression of TACR3 at the cellular level in oral squamous cell carcinoma. Our findings are as follows: (i) TACR 3 expression was observed in oral squamous cell carcinoma, (ii) TACR3 was not expressed in CK-13-positive normal epithelium, (iii) TACR3 staining was especially intense in the invasive front of oral squamous cell carcinoma in the bone matrix compared to the tumor cells located at the surface of the epithelium.

CK-13 (type I cytokeratin) is an important component of mucosal-stratified squamous epithelium and CK-13-positive cells are present during normal differentiation and keratinization $(18,19)$. In the present study, the expression of TACR3 was associated with CK-13-positive epithelial dysplasia, indicating that TACR3 may be involved in abnormal differentiation in dysplastic epithelia. CK-17 is also a type I cytokeratin that is expressed in oral squamous cell carcinoma and its expression is known to increase cell mobility and migration $(19,20)$. In this study, the CK-17 staining pattern was comparable to that of TACR3 in oral squamous cell carcinoma. This indicated that TACR3 may represent a highly specific marker for detecting neoplastic lesions, as it is associated with a marker for mobility and migration in oral squamous cell carcinoma.

TAC1 is a major excitatory neurotransmitter in the peripheral nervous system, while TAC3 is primarily involved in the CNS (21). In this study, histopathological examination demonstrated the importance of the expression of TAC 3 in peripheral nerve in the mandible. TAC3 may play roles not only as neurotransmitters but also as local factors and are involved in almost all aspects of the regulation of physiological functions and pathophysiological processes. TAC3 signaling 


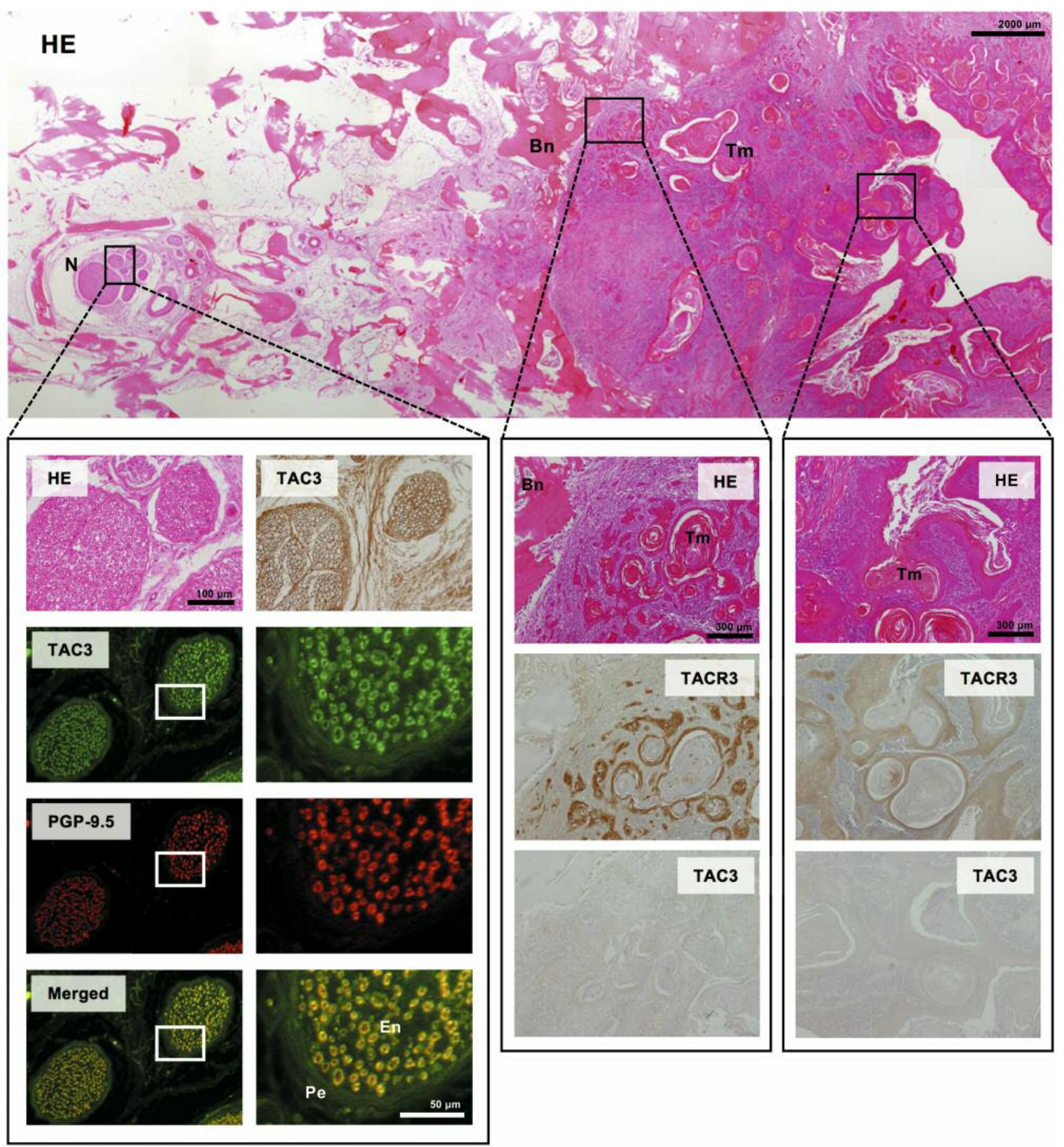

Figure 4. HE staining, immunofluorescence and immunohistochemistry results for TAC3, TACR3 and PGP-9.5 in resected mandible affected by lower gingival oral squamous cell carcinoma. $N$, inferior alveolar nerve; Bn, bone; Tm, tumor; En, endoneurium; Pe, perineurium; Bar, 150 um.

system in the cancer bone microenvironment has been shown the possibility to play a crucial role in the regulation of tumor, but molecular biological studies are needed to elucidate novel function of TAC3 in tumor invasion in the bone matrix.
Expression of TACR3 seems to be regulated by estrogens in central and peripheral levels (22). Estrogen-related receptor alpha (ESRRA) has been shown to be up-regulated in several cancers such as breast, prostate, ovarian, colon and 
oral squamous cell carcinoma (23-28). Further, ESRRA is known to promote the migration and invasion of oral squamous cell carcinoma (28). These observations suggest that TACR3 expression is upregulated by ESRRA signaling and that TACR3 has a role in tumorigenesis. Further studies analyzing estrogen levels from patient serum may establish an association between estrogen levels and TACR3 expression in human oral squamous cell carcinoma. Although the mechanism by which TACR3 expression is involved in oral squamous cell carcinoma is unknown, TACR3 protein showed a clear and significant overexpression compared with the adjacent normal epithelium, particularly in the invasive front of the tumor in the bone matrix. Bone resorption releases growth factors from the bone matrix, including estrogen that may further upregulate TACR 3 in cells at the invasive front of tumors.

In summary, we have shown for the first time that TACR3 is highly expressed in the invasion front of oral squamous cell carcinoma in bone matrix. It is possible that TAC3 released by the peripheral sensory nerves may act in tumor cells and that TACR3 signaling may, in turn, contribute to tumor progression; however, further investigation is needed.

\section{Acknowledgements}

The Authors thank Dr. Eriko Aoyama for useful input. This work was supported by a Grant-in-Aid for Scientific Research (B) (JP26293428) (to T.S.) from the Ministry of Education, Culture, Sports, Science, and Technology of Japan.

\section{References}

1 Almeida TA, Rojo J, Nieto PM, Pinto FM, Hernandez M, Martín JD and Candenas ML: Tachykinins and tachykinin receptors: structure and activity relationships. Curr Med Chem 11: 20452081, 2004.

2 Satake H and Kawada T: Overview of the primary structure, tissue-distribution, and functions of tachykinins and their receptors. Curr Drug Targets 7: 963-974, 2006.

3 Corsetti M, Akyuz F and Tack J: Targeting tachykinin receptors for the treatment of functional gastrointestinal disorders with a focus on irritable bowel syndrome. Neurogastroenterol Motil 27: 1354-1370, 2015.

4 Ichiki T, Kuroishi KN, Gunjigake KK, Kobayashi S and Goto T: Neurokinin B activates the formation and bone resorption activity of rat osteoclasts. Neuropeptides 45: 239-244, 2011.

5 Langlois X, Wintmolders C, te Riele P, Leysen JE and Jurzak M: Detailed distribution of Neurokinin 3 receptors in the rat, guinea pig and gerbil brain: a comparative autoradiographic study. Neuropharmacology 40: 242-253, 2001.

6 Rigby M, O'Donnell R and Rupniak NM: Species differences in tachykinin receptor distribution: further evidence that the substance $\mathrm{P}$ (NK1) receptor predominates in human brain. J Comp Neurol 490: 335-353, 2005.

7 Rance NE: Menopause and the human hypothalamus: evidence for the role of kisspeptin/ neurokinin B neurons in the regulation of estrogen negative feedback. Peptides 30: 111-122, 2009.
8 Lehman MN, Coolen LM and Goodman RL: Kisspeptin/ neurokinin B/ dynorphin (KNDy) cells of the arcuate nucleus: a central node in the control of gonadotropin-releasing hormone secretion. Endocrinology 151: 3479-3489, 2010.

9 Topaloglu AK, Reimann F, Guclu M, Yalin AS, Kotan LD, Porter KM, Serin A, Mungan NO, Cook JR, Ozbek MN, Imamoglu S, Akalin NS, Yuksel B, O'Rahilly S and Semple RK: TAC3 and TACR3 mutations in familial hypogonadotropic hypogonadism reveal a key role for Neurokinin B in the central control of reproduction. Nat Genet 41: 354-358, 2009.

10 Semple RK and Topaloglu AK: The recent genetics of hypogonadotrophic hypogonadism - novel insights and new questions. Clin Endocrinol 72: 427-435, 2010.

11 Grachev P, Millar RP and O'Byrne KT: The role of neurokinin $\mathrm{B}$ signalling in reproductive neuroendocrinology. Neuroendocrinology 99: 7-17, 2014.

12 Millar RP and Newton CL: Current and future applications of $\mathrm{GnRH}$, kisspeptin and neurokinin B analogues. Nat Rev Endocrinol 9: 451-466, 2013.

13 Baik CS, Strauss GM, Speizer FE and Feskanich D: Reproductive factors, hormone use, and risk for lung cancer in postmenopausal women, the Nurses' Health Study. Cancer Epidemiol Biomarkers Prev 19: 2525-2533, 2010.

14 Egloff AM, Rothstein ME, Seethala R, Siegfried JM, Grandis JR and Stabile LP: Cross-talk between estrogen receptor and epidermal growth factor receptor in head and neck squamous cell carcinoma. Clin Cancer Res 15: 6529-6540, 2009.

15 Langevin SM, Grandis JR and Taioli E: Female hormonal and reproductive factors and head and neck squamous cell carcinoma risk. Cancer Lett 310: 216-221, 2011.

16 Cejudo Roman A, Pinto FM, Dorta I, Almeida TA, Hernández M, Illanes M, Tena-Sempere M and Candenas L: Analysis of the expression of neurokinin B, kisspeptin, and their cognate receptors NK3R and KISS1R in the human female genital tract. Fertil Steril 97: 1213-1219, 2012.

17 Cañete H, Dorta I, Hernández M, Cejudo Roman A, Candenas L, Pinto FM, Valladares F, Báez D, Montes de Oca F, Bello AR and Almeida TA: Differentially regulated expression of neurokinin $B$ (NKB)/NK3 receptor system in uterine leiomyomata. Hum Reprod 28: 1799-1808, 2013.

18 Moll R, Divo M and Langbein L: The human keratins: biology and pathology. Histochem Cell Biol 129: 705-733, 2008.

19 Nobusawa A, Sano T, Negishi A, Yokoo S and Oyama T: Immunohistochemical staining patterns of cytokeratins 13, 14, and 17 in oral epithelial dysplasia including orthokeratotic dysplasia. Pathol Int 64: 20-27, 2014.

20 Sakamoto K, Aragaki T, Morita K, Kawachi H, Kayamori K, Nakanishi S, Omura K, Miki Y, Okada N, Katsube K, Takizawa $\mathrm{T}$ and Yamaguchi A: Down-regulation of keratin 4 and keratin 13 expression in oral squamous cell carcinoma and epithelial dysplasia: a clue for histopathogenesis. Histopathology 58: 531542, 2011.

21 Onaga T: Tachykinin: recent developments and novel roles in health and disease. Biomol Concepts 5: 225-243, 2014.

22 Navarro VM1, Ruiz-Pino F, Sánchez-Garrido MA, GarcíaGaliano D, Hobbs SJ, Manfredi Lozano M, León S, SangiaoAlvarellos S, Castellano JM, Clifton DK, Pinilla L, Steiner RA and Tena-Sempere M: Role of neurokinin B in the control of female puberty and its modulation by metabolic status. J Neurosci 32: 2388-2397, 2012. 
23 Ariazi EA, Clark GM and Mertz JE: Estrogen-related receptor alpha and estrogen-related receptor gamma associate with unfavorable and favorable biomarkers, respectively, in human breast cancer. Cancer Res 62: 6510-6518, 2002.

24 Cavallini A, Notarnicola M, Giannini R, Montemurro S, Lorusso D, Visconti A, Minervini F and Caruso MG: Oestrogen receptorrelated receptor alpha (ERRalpha) and oestrogen receptors (ERalpha and ERbeta) exhibit different gene expression in human colorectal tumour progression. Eur J Cancer 41: 14871494, 2005.

25 Cheung CP, Yu S, Wong KB, Chan LW, Lai FM, Wang X, Suetsugi M, Chen S and Chan FL: Expression and functional study of estrogen receptor-related receptors in human prostatic cells and tissues. J Clin Endocrinol Metab 90: 1830-1844, 2005.

26 Sun P, Sehouli J, Denkert C, Mustea A, Könsgen D, Koch I, Wei $\mathrm{L}$ and Lichtenegger W: Expression of estrogen receptor-related receptors, a subfamily of orphan nuclear receptors, as new tumor biomarkers in ovarian cancer cells. J Mol Med 83: 457-467, 2005 .
27 Mori T, Sawada M, Kuroboshi H, Tatsumi H, Katsuyama M, Iwasaku $\mathrm{K}$ and Kitawaki J: Estrogen related receptor $\alpha$ expression and function are associated with vascular endothelial growth factor in human cervical cancer. Int J Gynecol Cancer 21: 609-615, 2011.

28 Tiwari A, Shivananda S, Gopinath KS and Kumar A: MicroRNA-125a reduces proliferation and invasion of oral squamous cell carcinoma cells by targeting estrogen-related receptor $\alpha$ : implications for cancer therapeutics. J Biol Chem 289: 32276-32290, 2014.
Received October 3, 2016

Revised October 19, 2016

Accepted October 21, 2016 